\title{
Ciudad de los condenados: \\ Lima en el cine peruano a fines de los ochenta y comienzos de los noventa
}

\author{
Emilio Bustamante (Universidad de Lima) \\ Recibido: 14/12/08 \\ Aprobado: 15/01/09
}

RESUMEN: Se examina la representación de la ciudad de Lima como ámbito siniestro, carcelario y mortuorio en tres películas peruanas de fines de los años ochenta y comienzos de los noventa: Juliana (1989), Caídos del cielo (1990) y Alias La Gringa (1991). Se vincula esa representación con el contexto político, económico y social en el que los filmes fueron producidos.

Palabras clave: Lima - cine peruano - guerra interna - representación

City of the dammed. Lima in the late eighties cinema and beginning of the nineties

SUMMARY: The article examines the representation of Lima as a sinister, prisonlike and grim environment in three peruvian movies from the end of the eighties and beginning of the nineties: Juliana (1989), Caídos del cielo (1990) and Alias La Gringa (1991). This illustration is then related to the political, economic and social context on which the films were produced.

Key words: Lima - Peruvian cinema - internal war - representation 
E n su libro Cine e historia, Michele Lagny sostiene que el cine puede ser indicativo de cómo una sociedad se imagina a sí misma y se escenifica en determinado momento. ${ }^{1}$ La escenificación supone, por cierto, un espacio de representación, que alude sin embargo a otro espacio mayor, el espacio representado. En el caso de varias películas peruanas de fines de los años ochenta y comienzos de los noventa, ese espacio representado era la ciudad de Lima. Aquí nos preguntamos, ¿cómo representaban a la ciudad de Lima los cineastas peruanos al final del primer gobierno de Alan García y al comienzo del primer gobierno de Fujimori?; ¿cuál era la imagen cinematográfica de la capital en momentos en que se vivía una guerra interna y una aguda crisis económica en el país?; ¿lucía la ciudad de Lima en esas películas estrenadas antes del estallido de la bomba en la calle Tarata como una urbe ajena a la violencia que azotaba los Andes o, por el contrario, era mostrada como una zona amenazada, si no ya totalmente invadida por la muerte?

Para responder estas preguntas hemos elegido analizar tres películas: Juliana (1989, Grupo Chaski); Caídos del cielo (1990, Francisco J. Lombardi); y Alias La Gringa (1991, Alberto Chicho
Durant). Los directores de las películas escogidas eran artistas de clase media, y, aunque provenían de distintos lugares de dentro y fuera del país, residían todos en Lima. Su representación de la ciudad en esa coyuntura histórica tiene, como se verá al final, muchas coincidencias; y se podría argüir por ello que correspondía a la de un grupo social más bien pequeño. Sin embargo, la muy buena acogida que tuvieron esas películas de parte de un público peruano numeroso y variado, indicaría acaso que esa representación era aceptada y compartida por sectores sociales más amplios que aquellos de los que provenían los realizadores de los filmes.

El análisis será básicamente narrativo y estilístico sobre la base de la propuesta de Marc Ferro (1980), quien sugiere la búsqueda de significados explícitos e implícitos en argumento y lenguaje de las representaciones.

Como premisa digamos que en la representación de una ciudad en el cine predominan dos figuras retóricas: la sinécdoque y la metáfora. Por la sinécdoque se alude a un todo por las partes; se invita al espectador a construir mentalmente una ciudad a partir de los retazos escogidos por el narrador. La ciudad imaginada, a su vez, puede ser metáfora de prisión o

1 LAGNY, Michele. Cine e historia. Problemas y métodos en la investigación cinematográfica, 1997, p. 201. 
libertad, de amor y muerte, de razón o locura, de desaliento o deseo.

\section{Juliana: La búsqueda de la ciudad utópica}

Juliana (1989, Grupo Chaski) cuenta la historia de una niña que trabaja vendiendo flores en el cementerio. La relación con su padrastro es muy conflictiva, lo que la lleva a huir del hogar y unirse a un grupo de niños de la calle que son incitados al robo y explotados por un delincuente llamado don Pedro. Como la banda solo admite varones, Juliana tiene que disfrazarse de hombre para ser admitida. Los abusos de don Pedro se acentúan y Juliana se rebela, pero es descubierta como mujer. Aún así logra asumir el liderazgo del alzamiento, reducir al delincuente y alcanzar la libertad para ella y sus compañeros. Todos los niños terminan viviendo de modo autogestionario en una bolichera abandonada, y uno de ellos, El Loco, quien posee cualidades de profeta, sueña que él y sus amigos viajan en un ómnibus que ilumina la urbe, conducido por un caritativo chofer.

En Juliana la idealización modaliza la denuncia social. Su final esperanzador la hace una película optimista; sin embargo, la cinta ubica sus acciones iniciales en el ambiente del cementerio Presbítero Maestro. Juliana trabaja allí colocando flores en las tumbas, y las primeras imágenes nos muestran un camposanto donde hay mucha gente realizando diferentes actividades, como si de una ciudad autónoma se tratara, aludiéndose en cierto modo a la presencia ya corriente de los muertos en la vida cotidiana de los limeños. Cuando Juliana termina su jornada de trabajo, sale acompañada de una amiga, y en primer término resaltan las rejas del cementerio-ciudad como si fueran las de una prisión. La doble representación de la ciudad como cementerio y prisión la reencontraremos en Caídos del cielo y Alias La Gringa.

Sin embargo, en Juliana se ven imágenes de una parte de la ciudad que no será visible en las otras dos películas mencionadas: la Lima pobre de los asentamientos humanos creados por inmigrantes, que habita la protagonista. Su vivienda está construida con tablas y adobe, algunas casas vecinas con esteras, las calles no están pavimentadas y cuelgan de lado a lado de ellas, en cordeles, cadenetas y ropa recién lavada; todo tiene una pátina de polvo, y se halla gastado por el uso. La ubicación del lugar es imprecisa: ¿es el norte, el este o el sur de Lima? El trayecto que realiza Juliana a pie para llegar al cementerio hace aparecer, no obstante, al asentamiento como cercano al centro. El interior de la casa de Juliana es relativamente amplio, pero la acumulación de objetos lo torna incómodo; además es oscuro. La oscuridad e incomodidad de la vivienda (y del vecindario, en general) contrasta con la claridad y la 
amplitud del cementerio donde, después del trabajo, la protagonista juega al fútbol con sus amigos. En Juliana empiezan así a invertirse los valores: el cementerio pierde momentáneamente la significación originalmente otorgada de muerte y prisión en contraste ahora con la casa y el barrio de la protagonista; y es, incluso, escenario de recreo infantil.

Pero este valor positivo del cementerio se revela ilusorio. En Juliana son pocos los planos que remiten a la violencia política de esos años, pero son fundamentales; y tienen lugar en un momento en el que Juliana presencia el sepelio de un efectivo militar. Ella y los demás niños que laboran en el cementerio lucen cabizbajos y atemorizados por esa aparición inmediata de la muerte, que parece hacerles tomar conciencia, por un rato, del carácter luctuoso del espacio que frecuentan (o prácticamente habitan). En la misma secuencia, la cámara recorre los nichos vacíos, aún por llenar; y en uno de ellos se lee la inscripción: PCP. Siguen tomas en contraluz de las estatuas del cementerio que enfatizan el sentido ominoso del lugar. En una escena posterior, previa a la partida de Juliana del cementerio y de su hogar, se repetirá el trayecto de la cámara por los nichos vacíos, y en el último de ellos un espejo le devolverá su imagen a la protagonista, quien se cortará el cabello ante él, transformándose, es decir, resucitando. Juliana, niega así a la muerte y va en busca de la vida; de su vida.

La imagen de la ciudad en Juliana puede rastrearse, más allá de los planos semidocumentales de las calles limeñas, en los grandes espacios en los que se desarrolla la existencia de la protagonista, los mismos que se hallan asociados también, en su mayoría, a figuras paternas que devienen ausentes, fallidas o ilusorias. Hay en el filme una búsqueda infructuosa de una autoridad legítima, que va develando una ciudad caótica e insegura. El cementerio remite a un presente de muerte pero a la vez al padre desaparecido. La estrechez y sordidez del asentamiento humano al padrastro y la violencia doméstica. Estos ambientes se dejan atrás para ingresar a la casa de don Pedro, antigua, grande, ruinosa, agrietada y húmeda, semejante a algunas viviendas del centro o de los barrios y distritos populares que le son vecinos, y que alude a un pasado mejor y a un presente miserable que los niños quieren alegrar con coloridos afiches. El Centro Comercial Arenales que recorren los ladronzuelos reclutados por don Pedro, representa en cierto modo a la utopía del mercado; los niños sueñan con lo que les es negado, pero el sueño se transforma en pesadilla, y el lugar se torna ajeno, laberíntico y adverso: un ascensor "atrapa" a un niño después de un hurto, "entregándolo" a un policía. La playa, de otro lado, es el espacio de 
libertad, y los niños - que han escapado ya de la tiranía de don Pedrodeciden vivir de frente al mar (en una ciudad que tradicionalmente le da la espalda). La bolichera, precaria pero acogedora, habitada por emprendedores infantes, expresa la confianza en un futuro feliz. El sueño de El Loco, por último, supone la puesta en marcha de un ideal utópico propio: la bolichera es aún una nave inmóvil, en el mejor de los casos a punto de partir; el ómnibus es ya un vehículo en movimiento. Es el ideal que se abre paso, iluminando la ciudad nocturna, borrando cualquier atisbo siniestro en ella, y dándole, en cambio, un resplandor maravilloso.

El final ilusionado y la apuesta por la utopía de Juliana, no dejan de ser, sin embargo, inquietantes. Si los principales espacios citadinos aparecen vinculados a una figura paterna (el cementerio al padre muerto, el asentamiento humano incómodo al padrastro, la casona en ruinas a Pedro, y la ciudad iluminada de la utopía al chofer del ómnibus), el ansia de hallar a ese chofer, es decir, a un conductor, un padre bueno que guíe a los niños, tiene algo de mesiánica, y sabemos que el anhelo de un mesías pueden degenerar en el respaldo a un dictador. Juliana está fechada en 1989; al año siguiente, el país eligió a Fujimori.

\section{La ciudad como cementerio: Caídos del cielo}

En Caídos del cielo (1990, Francisco J. Lombardi) se cuentan tres historias que se entrelazan. En una de ellas, don Ventura, un locutor radial de rostro desfigurado, que emite mensajes optimistas en una emisora limeña, salva de morir a una enigmática muchacha suicida a la que llama Verónica. Don Ventura se muestra atraído hacia Verónica, quien lo rechaza, agobiada por un pasado secreto y supuestamente terrible. Una noche, don Ventura descubre en el cuerpo de la chica dormida una espantosa cicatriz. En adelante es él quien la rehuye. Al verse rechazada, Verónica se suicida. En otra de las historias los ancianos señores Lizardo y Cucha Díaz Canseco venden todas sus propiedades y acaban en un asilo a fin de construir el mausoleo donde descansarán sus restos junto a los de su adorado hijo, muerto años antes.

En la tercera historia, basada en el cuento Los gallinazos sin plumas de Julio Ramón Ribeyro, una anciana ciega obliga a sus nietos a alimentar a un gigantesco cerdo con la esperanza de venderlo y obtener así dinero para su operación a los ojos. A la mujer no le importa que sus nietos enfermen con tal de alcanzar su objetivo. Al final uno de ellos la arroja al corral donde el cerdo la devora. 
La película comienza con contrapicados de altos y lujosos edificios, para mostrar más adelante tugurios y mercados con una cámara a nivel, creando una sensación de descenso físico y social. Los personajes de la cinta son, todos, seres que han tenido un pasado de bienestar pero que ahora se encuentran en una situación de decadencia. Don Ventura tuvo antes un rostro inmaculado; Verónica, con apariencia de chica de clase media, también ha tenido aparentemente un mejor ayer, del cual no obstante oculta una herida; los señores Díaz Canseco añoran la época en que poseían una hacienda y tenían a su hijo con vida; la ciega recuerda los años que sirvió a los Díaz Canseco en su era de esplendor, cuando aún podía ver; y los niños evocan el tiempo en el que su madre vivía con ellos, antes de partir hacia los Estados Unidos.

Cuando don Ventura acude al cementerio al final de la cinta para visitar la tumba de Verónica, vemos fechados los acontecimientos: 1989, inscrito en el nicho (apenas un año antes del estreno del filme). Se trata del último año del gobierno de Alan García, caracterizado por la hiperinflación, la baja del nivel adquisitivo, la escasez de alimentos, la especulación, el desempleo y el crecimiento de la arremetida senderista. Algunos pasajes de la cinta hacen referencia a este estado de cosas. Así, cuando los Díaz Canseco recorren sus propiedades (casas humildes cerca al mar, que bien podrían ubicarse en Magdalena) para cobrar la renta, reciben negativas de parte de los vecinos. Una de ellas dice: "hasta hoy los empleados públicos no han cobrado, si siguen así se irán a la huelga". Otra se queja: "el presidente, pues señora, tanto que prometía: los jubilados por aquí, los jubilados por allá, mire la porquería que nos están pagando". Y un sastre se lamenta: "¿Ahora quién se manda a hacer un buen terno, si no hay trabajo?". La única arrendataria que cumple con pagar su deuda es una especuladora a quien un hombre lleva clandestinamente un saco de arroz, y de cuyo domicilio se ve más tarde salir a otro individuo con una caja de leche. El contratista con el que don Lizardo ha pactado la construcción del mausoleo le dice que "los precios suben todos los días".

Los escenarios son muy pobres. La ciega vive con sus nietos en una solitaria choza de esteras cerca de un acantilado; no se trata ni siquiera de un asentamiento humano donde haya interacción con otras personas como el lugar que habitaba Juliana en la película del grupo Chaski. La casa de don Ventura (que es también una de las propiedades de don Lizardo) luce relativamente amplia, pero gastada y con un mobiliario humilde; los colores de las paredes y los muebles que componen el decorado son primarios (paredes azules, sillones rojos), pero la baja iluminación les da un tono más bien grotesco. 
Por su parte, la residencia de los ancianos (que podría estar en San Isidro), se queda prácticamente vacía cuando son enajenados los muebles para obtener el dinero suficiente que les permita pagar el mausoleo, y por último es también vendida.

Las tres historias concluyen con secuencias en cementerios: Don Ventura escribe el nombre de Verónica en el nicho donde han depositado su cadáver; los niños César y Tomás se miran, compartiendo el secreto y la culpa, ante la tumba de su abuela; y los Díaz Canseco admiran el mausoleo culminado. Los personajes de Lombardi, en este filme, caídos de un pasado mejor, tienen como presente la muerte. Habitan la muerte. Han realizado el trayecto inverso al que emprendió Juliana el año anterior. Descendieron de la utopía al cementerio. Y Lima no es solo una ciudad de muertos, sino de condenados: lo son don Ventura (un hombre de mediana edad), los ancianos y los niños. Para nadie existe un futuro distinto al abismo, y en ello ha sido muy explícito el personaje del locutor en el tramo final de la película cuando ha perorado: "A veces parece que existen seres tocados por el infortunio para los cuales no hay ni habrá esperanza"; casi una respuesta al primer ministro Juan Carlos Hurtado Miller, quien terminó su mensaje a la nación aquel año de 1990 con un patético: "Que Dios nos ayude".

\section{La ciudad y el terror:} Alias La Gringa

En Alias La Gringa (1991, Alberto Chicho Durant), el delincuente Jorge Venegas Peña, apodado La Gringa, quien escribe un diario de sus andanzas y es conocido por sus continuas fugas de los penales donde es recluido, huye de la cárcel para encontrarse con Julia, su amante, pero es recapturado y enviado a una isla penal. Allí, un profesor universitario apellidado Montes, acusado injustamente de subversivo, lo salva de morir a manos de otro recluso. La Gringa logra, más tarde, fugarse de la isla y planea con Julia un viaje a Guayaquil, pero al enterarse por una carta de que el profesor Montes había deseado huir con él, regresa a la isla penal para liberarlo y pagarle así su deuda de honor por haberle salvado la vida. Sin embargo, al retornar se encuentra con que el penal ha sido rodeado por fuerzas militares pues los presos por subversión se han amotinado al planearse su traslado a una cárcel de alta seguridad. Se produce una matanza, el profesor es asesinado, pero La Gringa logra escapar con Julia a Guayaquil.

La película se centra en el personaje de La Gringa, pero el escenario en el que este se mueve alude a circunstancias políticas y sociales que pueden fecharse entre 1986 y 1990. El tema carcelario tiene aquí como referente la matanza de los penales de 1986 (concretamente el motín en la isla penal de 
El Frontón), con representaciones explícitas de los presos por subversión y su entorno (pabellones, asambleas y discurso político). Asimismo, a través de un personaje secundario (el profesor Montes), se alude a los reclusos injustamente procesados por terrorismo y a la ley de amnistía que por entonces estaba discutiéndose. Tangencialmente se toca el tema de los jóvenes universitarios acosados por las fuerzas del orden como sospechosos de subversión, y se sugiere la existencia de autoridades represivas y corruptas. Por último, a un nivel menos explícito, pero quizá más trascendente, se proyecta la imagen de una ciudad capturada por el terror, no muy distinta (o acaso peor) que una cárcel.

\section{La ciudad siniestra}

La película comienza con una fuga de La Gringa. Luego se ve un gran plano general de Lima de noche, con el cerro San Cristóbal al fondo. Escuchamos el sonido de una sirena. A continuación vemos un vehículo de bombero cruzar la pantalla. La impresión es la de una ciudad en emergencia. Más adelante distinguimos las luces rojas de las circulinas de los autos patrulleros y escuchamos silbatos. Es el centro de Lima: alcanzamos a distinguir el hotel
Bolívar y la avenida La Colmena. La gente se agolpa en las veredas, curiosa, mientras los policías con armas en ristre caminan alertas, cuidando negocios con vitrinas que parecen muy vulnerables en calles que lucen descuidadas, llenas pedazos de papel y desperdicios. Desde el interior de un auto, en un travelling, logramos avizorar entonces una camioneta de la Unidad de Desactivación de Explosivos (UDE) y a un policía con un extraño casco (que lo hace aparecer como un ser extraterrestre) de pie frente a un poste de luz. Vemos más policías armados, y ya con cámara fija al policía del casco desactivando una bomba al pie del poste. Otros guardias de seguridad cruzan ahora la pantalla en motocicletas con luces rojas, rondando las sucias calles. Nos preguntamos: ¿es esta la Lima que conocemos? Y luego, ¿es este el espacio de libertad hacia donde ha huido La Gringa?

En la secuencia descrita, podemos reconocer Lima, pero también podemos ver en ella una ciudad distinta y atemorizante. Esta visión de algo ya conocido pero que a la vez es diferente y que infunde angustia o miedo se adecua al concepto de "lo siniestro" enunciado por Freud: "Lo siniestro sería aquella suerte de espantoso que afecta las cosas conocidas y familiares desde tiempo atrás". 2

2 FREUD, Sigmund. Obras completas. Vol. 13, 1988, p. 2484. 
Freud amplía en el mismo artículo el concepto, señalando que "lo siniestro no sería realmente nada nuevo, sino más bien algo que siempre fue familiar a la vida psíquica y que solo se tornó extraño mediante el proceso de represión", para luego añadir que este vínculo con la represión ilumina la definición de Schelling según la cual "lo siniestro sería algo que, debiendo haber quedado oculto, se ha manifestado"3 ${ }^{\prime 2}$ En el caso de Lima, en Alias La Gringa, la ciudad es aparentemente la misma (las mismas calles, los mismos edificios), pero lo que estaba oculto o reprimido se halla ahora desatado; la violencia latente se ha hecho explícita. ${ }^{4}$
La definición de lo siniestro como la reaparición (la repetición) de algo que se tenía por superado o sepultado implica la generación de una gran angustia en quien lo experimenta. En el caso específico de Alias La Gringa, el personaje reencuentra en Lima la misma violencia y falta de libertad que en la cárcel.

Al fugar no ha vencido el encierro; la Lima a la que va a caer no es sino la continuación de la prisión. Cuando ya ha creído escapar, se da cuenta de que está todavía preso. Otros aspectos de la ciudad que a continuación ilustra el filme ratifican esta imagen de Lima como una prolongación del penal.

3 Ibídem, p. 2498.

4 En una película realizada años después, Sin compasión (1994, Francisco J. Lombardi), volvería a mostrarse Lima como una ciudad siniestra. Se trataba de una adaptación de Crimen y castigo de Dostoievski, donde Ramón Romano, un pobre y aplicado estudiante de Derecho, vive agobiado por las deudas y el desprecio de seres que considera inferiores a él. Fiel a sus lecturas de Nietszche sostiene que un hombre superior debe ser capaz de hacer justicia por su propia mano sin sentir por ello remordimiento. Es así como da muerte a su desagradable casera y al marido de esta, pero el mayor de policía Saúl Portillo sospecha de él. De otro lado, Ramón ha conocido a una joven prostituta, Sonia, por quien siente una profunda piedad que trastoca luego en amor. Sonia, a su vez, es acosada por Velaochaga, un lúbrico abogado obsesionado por la joven.

El filme se desarrolla en un ambiente sombrío. Los barrios de Lima que se ven en ella son los del centro de la capital o los del Rímac y Barrios Altos, zonas antiguas y muy empobrecidas. La cámara capta los portales viejos y carcomidos y los interiores húmedos y grises. Quienes habitan estos lugares parecen tan huérfanos o caídos del cielo como los de la película anterior de Lombardi. La fotografía y la dirección artística enfatizan la monocromía de los espacios. Puede decirse que estos expresan una visión interior, la oscura y desencantada perspectiva de Ramón Romano, cuyo relato en primera persona articula el filme; pero la ciudad de Lima es visible y reconocible, no se trata de cualquier construcción mental o de una urbe abstracta. Velaochaga, el sinuoso abogado que acosa a Sonia, dice acerca de Ramón: “Para mí que está algo mal de la cabeza. No lo culpo. Un chico tan sensible viviendo en esta inmundicia. Lima es una ciudad de locos: el hambre, la rabia, la desesperación [...]". Más tarde, Velaochaga se suicidará en pleno centro de la ciudad, en las escalinatas de la catedral, demostrando que es también una víctima de esa ciudad como de sus propias pasiones. 


\section{La ciudad prisión}

En la tercera secuencia del filme vemos a La Gringa en un taxi. El interior del vehículo está iluminado de rojo. Se escucha en la radio del auto el siguiente reporte:

Fuerzas especiales de la policía desactivaron un artefacto explosivo en una calle céntrica de la ciudad [...]. Un diputado del parlamento nacional fue asesinado a balazos por manos terroristas esta tarde. Más de quince mil sospechosos han sido detenidos en el operativo desatado para detener a los responsables de este repudiable crimen [...]. Ahora el momento de la oración con el reverendo padre José María Salcedo.

El reporte no tiene pierde. Primero hace un recuento de lo que hemos visto en la secuencia anterior, luego informa de un crimen político, y el operativo suena dantesco (quince mil detenidos); a continuación pareciera que solo quedase rezar (la entrada del sacerdote para el momento de la oración).

Una vez que se ha escuchado este reporte se sostiene un breve diálogo entre el taxista y La Gringa.

Taxista: Mucha violencia, ¿no?

Gringa: Mucha.

Taxista: Demasiada, ¿no?

La Gringa asiente y pretexta luego bajar a comprar unos cigarrillos, pero el taxista adivina que quiere irse sin pagar y lo amenaza con un cuchillo. La Gringa paga con un reloj y el taxista le da el vuelto. Hay una mirada de entendimiento entre ambos, como si compartieran un mismo código criminal, semejante o igual al de una prisión.

\section{El estallido}

Después de su segunda fuga, La Gringa, ayudado por Julia, se refugia en una vetusta quinta de un solo caño en el centro de Lima donde, según la misma Julia, la mayoría de los inquilinos son estudiantes.

En el lugar se produce, luego, un allanamiento por parte de la policía. La Gringa se esconde. Uno de los guardias aparece en la puerta de uno de los cuartos con un manojo de papeles, exclamando: "ipropaganda subversiva!". Cuando termina el operativo y La Gringa retorna a su habitación, escribe, y una voice over nos informa del contenido de su texto:

Antes no tenía tanto miedo [...]. Antes no tenía miedo. Me fugaba pensando que me podían agarrar de nuevo. Pero ahora tengo miedo, miedo de todo, hasta de escribir. No sé por qué.

En la escena siguiente, de inmediato, por corte seco, La Gringa aparece atento a un programa de televisión en donde se ve primero a una reportera hablando entre lenguas de fuego y a continuación imágenes de curiosos contenidos por policías en frente de un auto en llamas. Es la única vez que 
se ven, en el filme, casas de esteras, pertenecientes a la Lima alejada del centro, Callao y los balnearios. El texto de la reportera es el siguiente:

El guardián ha declarado que el coche-bomba fue dejado alrededor de las 11 de la noche. Estalló dos horas más tarde, lo que demuestra que los terroristas manejan un sofisticado sistema de detonación. Una nueva operación rastrillo acaba de comenzar. Desde el lugar de los hechos informó para TV-3, Marisol Palacios.

Durante la escena se alternan las imágenes de la televisión con primeros planos muy cerrados de La Gringa, tenso y contrariado. Al final de la escena un locutor informa:

[...] volvieron a subir la medicinas, los mineros del ande central inician una marcha de sacrificio a Lima exigiendo mejoras salariales y un turista fue detenido en el aeropuerto internacional de Lima acusado de querer salir del país con un kilo de cocaína.

La sintaxis de la escena parece explicar la sensación de miedo de La Gringa como producto del ambiente de violencia en el que se encuentra inmerso. Como en una película de horror (véase, por ejemplo, En la boca de la locura de John Carpenter), toda fuga lo devuelve al mismo ambiente. Lo que ha creído que ha dejado atrás aparece al siguiente paso sobredimensionado. La Gringa experimenta la angustia provocada por lo siniestro.
La ciudad además se halla cercada: la marcha de sacrificios de mineros trae los Andes a una capital sin medicinas cuya salida se está cerrando (la mención al turista que no puede irse por traficar con cocaína no parece gratuita).

Al final del filme es evidente que la ciudad se encuentra amenazada por fuera y por dentro. Está siendo cercada por manifestantes, y en sus calles hay fuerzas que han emergido y colocan bombas que antes eran desactivadas a duras penas por la policía, y que ahora han empezado a explosionar.

La comparación con la cárcel se acentúa: la isla penal se halla rodeado por militares a punto de bombardearla, y los presos amotinados se encuentran dispuestos a combatir con armas y dinamita. El penal termina por estallar; la ciudad está a punto de hacerlo. Al año siguiente de Alias La Gringa tuvo lugar el atentado de la calle Tarata en Miraflores.

\section{Algunas conclusiones}

Lima es representada en Alias La Gringa y Caídos del cielo con valores negativos: es prisión (Alias La Gringa), y cementerio (Caídos del cielo).

En Caídos del cielo hay énfasis en la significación de decadencia vinculada la ciudad: hubo un pasado mejor, y el presente es miserable y abyecto. La ciudad decadente es representada por viejos edificios carcomidos, calles vetustas, etcétera. 
En Alias La Gringa la ciudad resulta siniestra: se le reconoce pero a la vez se le percibe distinta, y esa nueva percepción causa pánico.

En esta película la comparación de la urbe con la prisión se vuelve escalofriante cuando la isla penal estalla por acción de la violencia subversiva y contrasubversiva, anticipando el inminente estallido de la ciudad misma.

En las películas mencionadas la geografía de Lima se limita casi únicamente al centro, el Callao, los balnearios y los distritos antiguos de clase media y popular. Es decir, un paisaje imaginado de la ciudad más propio de los años cincuenta que de los ochenta o noventa. Incluso la casa de esteras donde viven la abuela y los nietos en Caídos del cielo recuerda a la Lima de los cincuenta, la de Los gallinazos sin plumas y Al pie del acantilado de Ribeyro. Solo en Juliana se representa un asentamiento humano creado por inmigrantes que podría remitir a una Lima más reciente, no obstante el barrio de Juliana parece también geográficamente muy cercano al centro tradicional.

Los efectos emocionales en Caídos del cielo y Alias La Gringa son notoriamente disfóricos: falta de libertad, muerte, terror, depresión, pánico. Solo Juliana es optimista; sin embargo, es cronológicamente la primera del período. La disforia y el pesimismo, aparentemente, fueron ganando terreno en la representación de la ciudad y del futuro de sus habitantes entre 1989 y 1991.

\section{Bibliografía}

FERRO, Marc. Cine e historia. Barcelona: Gustavo Gili, 1980.

FREUD, Sigmund. Obras completas. Vol. 13. Buenos Aires: Orbis, 1988.

LAGNY, Michele. Cine e historia. Problemas y métodos en la investigación cinematográfica. Barcelona: Bosch, 1997. 